\title{
Pengembangan Model Pembelajaran Adaptive Blended Learning untuk Berbagai Jenis Gaya Belajar Siswa Menengah Atas pada Pokok Bahasan Listrik Statis
}

\author{
Nuri Rimbawatia ${ }^{\mathrm{a}}$, Muchlas $^{\mathrm{b})}$ \\ Universitas Ahmad Dahlan, Jalan Pramuka 42, Sidikan, Umbulharjo, Yogyakarta 55161 \\ Email: ${ }^{\text {a)}}$ nuryrimbawati@yahoo.com, ${ }^{\text {b) }}$ muchlas.te@uad.ac.id
}

\begin{abstract}
Physics learning are currently given by using model and varied online media learning. However, that varied learning model is still rarely pay attention to students learning styles. Consequently, learning becomes less optimal and less motivated students. Rapidly information technology blooming gave a great opportunity for the development of online learning models that have the adaptive feature of the student's learning style. The aim of this research is to produce learning model blended learning, merger between models of online learning and faceto-face learning, adaptive by learning styles of students. This product was validated by experts consist of media experts and learning physics expert. The results showed that developed of learning model, according to experts has validated in good categories so that used in physics learning.
\end{abstract}

Keywords: model learning, blended learning, learning style

\begin{abstract}
Abstrak
Pelajaran fisika saat ini telah banyak diberikan dengan menggunakan model dan media pembelajaran online yang variatif. Namun, dari berbagai model pembelajaran tersebut masih jarang yang memperhatikan gaya belajar siswa. Akibatnya, pembelajaran menjadi kurang maksimal dan kurang memotivasi siswa. Perkembangan teknologi informasi yang sangat pesat telah memberikan peluang yang besar bagi pengembangan model pembelajaran online yang memiliki sifat adaptif terhadap gaya belajar siswa. Penelitian ini bertujuan menghasilkan model pembelajaran blended learning, yakni penggabungan antara model pembelajaran online dan pembelajaran face to face, yang adaptif sesuai gaya belajar siswa yang mengikutinya. Produk ini divalidasi oleh ahli yang terdiri atas: ahli media, dan ahli pembelajaran fisika. Hasil penelitian menunjukkan bahwa model pembelajaran yang dikembangkan, menurut para ahli memiliki validasi dalam kategori baik sehingga layak digunakan dalam pembelajaran fisika.
\end{abstract}

Kata-kata kunci: model pembelajaran, blended learning, gaya belajar.

\section{PENDAHULUAN}

Salah satu upaya untuk meningkatkan mutu pendidikan adalah dengan cara mengoptimalkan proses pembelajaran. Proses pembelajaran dipengaruhi oleh faktor internal dan faktor eksternal. Faktor eksternal yang paling mempengaruhi adalah faktor keadaan sekolah yang di dalamnya terdapat proses pembelajaran, kurikulum, materi, media, dan guru. Sedangkan untuk faktor internal yang mempengaruhi adalah kemampuan yang berbeda pada setiap siswa dalam memahami dan 
menyerap pelajaran yang disampaikan oleh guru. Siswa merupakan individu yang unik, artinya tidak ada dua orang siswa yang sama persis, tiap siswa mempunyai perbedaan satu sama lain.

Rita Dunn, seorang pelopor di bidang gaya belajar, telah menemukan banyak variabel yang mempengaruhi cara belajar orang. Ini mencakup faktor-faktor fisik, emosional, sosiologis, dan lingkungan (Mike 2005, p.110). Gaya belajar merupakan suatu kombinasi dari bagaimana seseorang menyerap dan kemudian mengatur serta mengolah informasi. Gaya belajar bukan hanya berupa aspek ketika menghadapi informasi, melihat, mendengar, menulis dan berkata tetapi juga aspek pemrosesan informasi sekuensial, analitik, global atau otak kiri dan otak kanan. Menurut Grinder, pengarang Risting The Education Conveyor Belt dalam Hasrul (2009) telah mengajarkan gaya-gaya belajar dan mengajar kepada banyak instruktur. Ia mencatat bahwa dalam setiap kelompok yang terdiri dari tiga puluh murid, sekitar dua puluh dua orang mampu belajar secara cukup efektif dengan cara visual, auditorial, dan kinestetik sehingga mereka tidak membutuhkan perhatian khusus. Dari sisa delapan orang sekitar enam orang memilih satu modalitas belajar dengan sangat menonjol melebihi dua modalitas lainnya. Sehingga, setiap saat mereka harus selalu berusaha keras memahami perintah, kecuali jika perhatian khusus diberikan kepada mereka dengan menghadirkan cara yang mereka pilih. Bagi orang-orang ini, mengetahui cara belajar terbaik mereka bisa berarti perbedaan antara keberhasilan dan kegagalan. Dua orang murid lainnya mempunyai kesulitan belajar karena sebabsebab eksternal.

Menurut Hermawanto, Kusairi \& Wartono (2013) salah satu permasalahan yang dihadapi oleh guru fisika dalam pembelajaran fisika adalah penguasaan konsep dan penalaran siswa masih rendah. Untuk itu perlu diubah paradigma pembelajaran menuju ke pembelajaran yang berorientasi student centered, melalui pembelajaran blended learning. Blended learning yaitu pembelajaran yang mengombinasikan pembelajaran tatap muka dengan pembelajaran online. Menurut Garnham, tujuan dikembangkannya blended learning adalah menggabungkan ciri-ciri terbaik dari pembelajaran di kelas (tatap muka) dan ciri-ciri terbaik pembelajaran online untuk meningkatkan pembelajaran mandiri secara aktif oleh siswa (Husamah 2013, p. 21). Yusuf (2011) menyatakan bahwa Blended learning sering digunakan untuk makna yang sama dengan istilah hybrid dan mix-learning. Tiga istilah ini secara praktis mengonvergensi bahan-bahan elektronik dengan interaksi di dalam kelas. Pendekatan ini menjadikan pembelajaran lebih personal dengan pemberian instruksi yang berbeda antara satu peserta dengan peserta yang lain.

Yusuf (2011), Blended learning merupakan pengembangan model-model e-learning yang dianggap pendekatan paling tepat memoderasi kebutuhan pembelajaran masyarakat terbuka terhadap perubahan global sekaligus memenuhi selera belajar tradisional yang belum bisa ditinggalkan. Pradnyawati, Suparta, \& Sariyasa (2014) menyatakan bahwa blended learning juga dapat memfasilitasi berbagai gaya belajar siswa, dimana masing-masing siswa mempunyai gaya belajar yang berbeda-beda. Hasil dari penelitian Pradnyawati menyatakan bahwa strategi pembelajaran blended learning baik untuk proses pembelajaran siswa sesuai dengan gaya belajar masing-masing siswa. Dengan blended learning, penguasaan konsep siswa menjadi lebih baik. Hermawanto, Kusairi, \&Wartono (2013) menyatakan bahwa penalaran peserta didik yang menggunakan blended learning lebih tinggi daripada konvensional.

Listrik statis merupakan materi untuk siswa menengah atas dengan standar kompetensi menerapkan konsep kelistrikan dan kemagnetan dalam berbagai penyelesaian masalah dan produk teknologi. Kompetensi dasarnya adalah memformulasikan gaya listrik, serta penerapannya pada keping sejajar. Sebagaimana mata pelajaran lain, listrik statis memiliki target ketercapaian dalam pembelajaran seperti yang diharapkan oleh kurikulum. oleh sebab itu, wajar bila guru yang mengajar berupaya untuk menjadikan pembelajarannya diminati, dapat diikuti dengan sikap antusias dan penuh percaya diri sehingga dapat memperoleh keberhasilan dalam pembelajaran. Dalam konteks demikian, diperlukan pendekatan/model pembelajaran blended learning yang inovatif, sehingga proses pembelajaran dapat berlangsung secara efektif dan menyenangkan. Dalam hal ini, siswa tidak hanya diajak untuk belajar dan berlatih serta mengerjakan tugas dalam konteks formal dan situasi ruangan kelas setiap hari, tetapi juga diajak untuk belajar dan berlatih secara online.

Atas dasar kenyataan tersebut, maka perlu dilakukan usaha-usaha pengembangan model pembelajaran yang bersifat adaptif sesuai dengan gaya belajar masing-masing siswa, menggunakan gabungan antara pembelajaran tatap muka dan online. Tujuan penelitian ini adalah merancang 
pembelajaran blended learning dengan media berbasis website yang sesuai dengan jenis gaya belajar masing-masing siswa Sekolah Menengah Atas untuk Pokok Bahasan Listrik Statis.

\section{METODE PENELITIAN}

Penelitian ini menggunakan metode Research and Development, yakni cara penelitian yang digunakan untuk menghasilkan produk tertentu, dan menguji keefektifan produk tersebut (Sugiyono 2009, p. 407). Produk penelitian ini adalah model pembelajaran blended yang berisi materi listrik statis, dilengkapi dengan media berbasis website, dan adaptif terhadap jenis gaya belajar siswa.

Prosedur yang digunakan mengacu pada model pengembangan ADDIE dengan alasan bahwa model ini sesuai untuk diterapkan dalam pengembangan media yang akan dihasilkan dalam penelitian ini. Prosedur pengembangan yang mengacu pada model pengembangan ADDIE terdiri atas analysis, design, development, implementation, and evaluation.

Analysis merupakan langkah awal dalam pengembangan media pembelajaran. Tahap ini digunakan untuk mengidentifikasi kebutuhan untuk menjamin bahwa produk yang dikembangkan sesuai dengan kebutuhan. Design, adalah tahap kegiatan yang meliputi pembuatan format atau pola yang dibutuhkan, penyiapan materi, pembuatan animasi, dan rancangan tampilan. Development, merupakan kegiatan perakitan program awal, pelaksanaan evaluasi program hingga menjadi media pembelajaran berbasis website yang siap diimplementasikan. Implementation, merupakan tahap nyata penerapan atau penggunaan program agar dapat dioperasikan, sedangkan evaluation merupakan proses akhir untuk menentukan kelayakan media oleh ahli media dan ahli materi.

Sesuai dengan klasifikasi jenis datanya, instrumen pengumpulan data pada penelitian ini terbagi dalam dua kategori yaitu instrumen untuk ahli media, dan instrumen untuk ahli materi. Instrumen pada penelitian ini berupa angket menggunakan skala Likert. Teknik analisis data pada penelitian ini menggunakan analisis deskriptif kualitatif. Analisis ini digunakan untuk menggambarkan karakteristik data pada masing-masing variabel. Dengan cara ini diharapkan dapat mempermudah memahami data untuk proses analisis selanjutnya. Hasil analisis data digunakan sebagai dasar untuk merevisi produk media yang dibuat. Teknik analisis kualitatif digunakan untuk memaparkan hasil produk media pembelajaran dalam tinjauan validasi dan kelayakan produk untuk diterapkan pada materi listrik statis. Arikunto (2010) menyatakan bahwa data yang terkumpul diproses dengan cara persentase. Menurut Ali (1995) untuk memperoleh persentase dari suatu nilai, dicari dengan menggunakan Persamaan (1):

$$
\mathrm{P}(\mathrm{s})(\%)=\frac{\mathrm{s}}{\mathrm{N}} \times 100
$$

Keterangan:

$\mathrm{P}(\mathrm{s}) \quad=$ persentase kelayakan $(\%)$

$\mathrm{s} \quad=$ skor yang diobservasi

$\mathrm{N} \quad=$ skor maksimum

Data yang dikumpul dianalisis dengan teknik analis deskriptif yang diungkapkan dengan distribusi skor dan persentase. Setelah dijadikan persentase selanjutnya dideskripsikan dan diambil kesimpulan tentang masing-masing indikator. Kriteria validasi yang digunakan pada penelitian ini ditunjukkan pada TABEL 1.

TABEL 1. Interval kriteria penilaian

\begin{tabular}{ccc}
\hline No & Interval & Kriteria kualitatif \\
\hline 1 & $0 \%-25 \%$ & Tidak baik \\
2 & $26 \%-50 \%$ & Kurang baik \\
3 & $51 \%-100 \%$ & Cukup baik \\
4 & $76 \%-100 \%$ & Baik \\
\hline
\end{tabular}




\section{HASIL DAN PEMBAHASAN}

Penelitian pengembangan model pembelajaran blended learning ini menghasilkan media pembelajaran berbasis website. Pada website terdapat angket untuk menentukan gaya belajar siswa. Gaya belajar mencakup gaya belajar visual, auditorial, dan kinestetik. Materi yang terdapat pada website mengacu pada setiap gaya belajar. Untuk gaya belajar visual materi disajikan dalam betuk bacaan dan gambar pada pokok bahasan listrik statis. Untuk gaya belajar auditori materi disajikan dalam bentuk suara rekaman penjelasan mengenai listrik statis. Sedangkan untuk gaya belajar kinestetik disajikan sesuai dengan gaya belajar kinestetik. Dalam hal ini, materi untuk gaya belajar kinestetik disajikan dalam bentuk percobaan simulasi, agar siswa dapat turut serta melakukan aktivitas pembelajaran. Evaluasi disajikan sama untuk semua jenis gaya belajar. Pada evaluasi terdapat skor yang dihasilkan oleh siswa pada saat mengerjakan evaluasi.

Website untuk pembelajaran listrik statis ini dapat diakses melalui http://www.listrikstatis.net. Setiap siswa dapat menggunakan media pembelajaran ini dengan menyantumkan Nomor Induk Siswa (NIS) dan Nama siswa tersebut. Pada tampilan awal terdapat ilustrasi kejadian awal mengenai listrik statis yang terdapat pada proses terjadinya petir. Tampilam awal media pembelajaran ini dapat dilihat pada GAMBAR 1 .

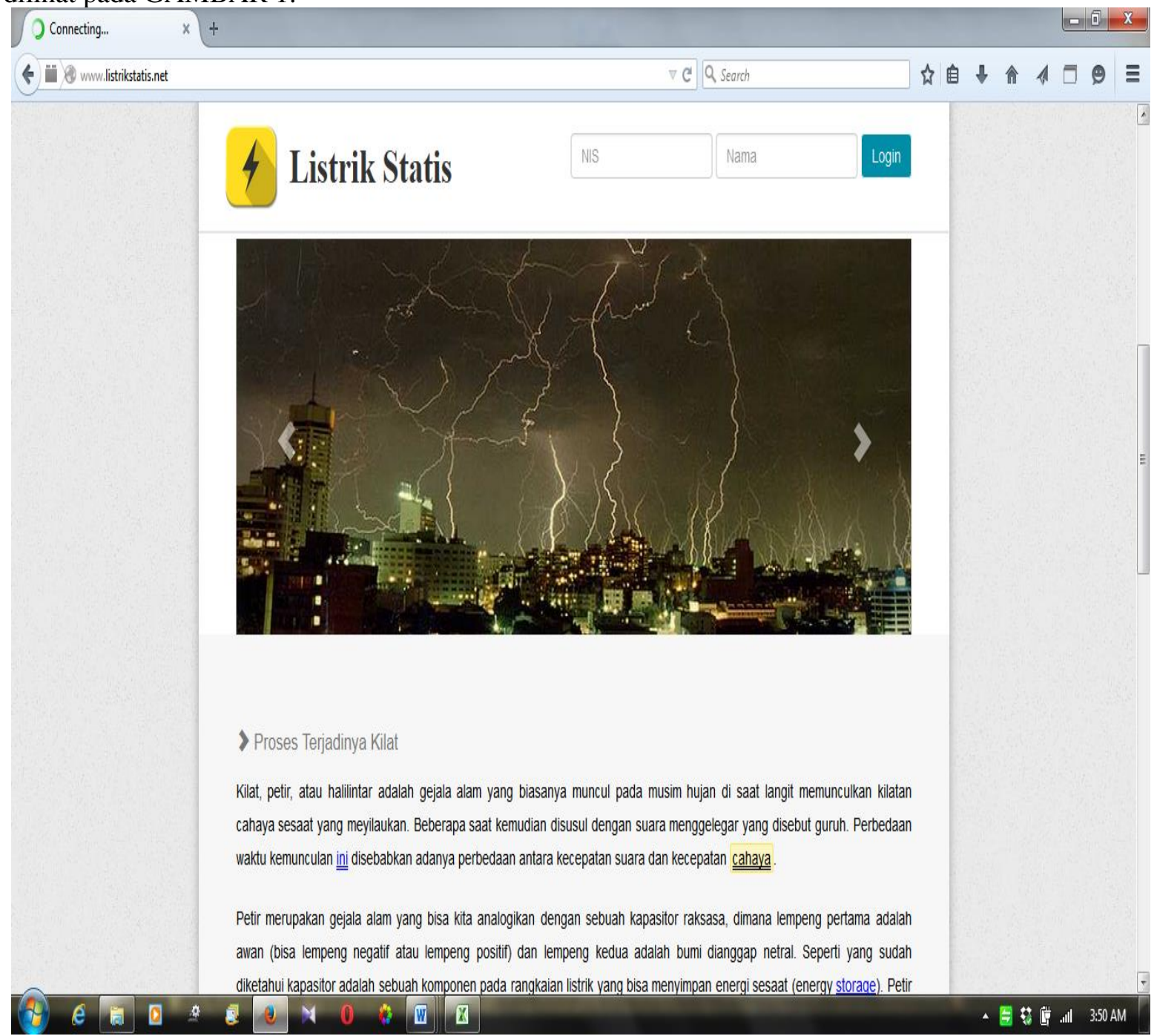

GAMBAR 1. Tampilan awal media pembelajaran listrik statis

Data uji coba pada penelitian ini adalah data uji validitas atau kelayakan revisi produk berdasarkan saran para ahli. Berdasarkan langkah uji coba, penelitian ini telah menghasilkan datadata dari para ahli yang bersifat kuantitaif dan kualitatif. Data-data tersebut digunakan untuk melakukan uji kelayakan produk sebagai landasan perbaikan produk yang akan dikembangkan. 
Data kuantitatif ahli media terhadap produk yang dikembangkan dapat dilihat pada TABEL 2. Untuk grafik data kuantitaif ahli media ditunjukkan pada GAMBAR 2(a).

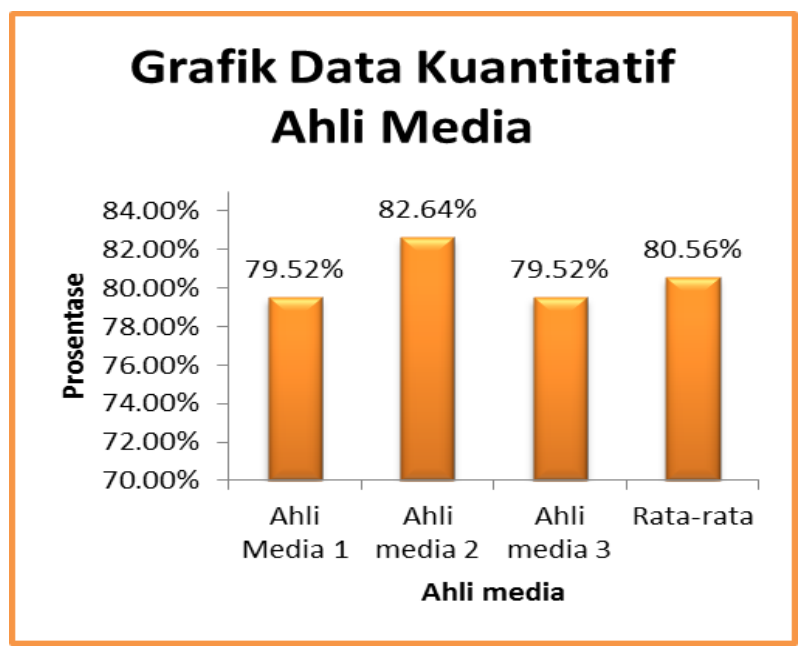

(a)

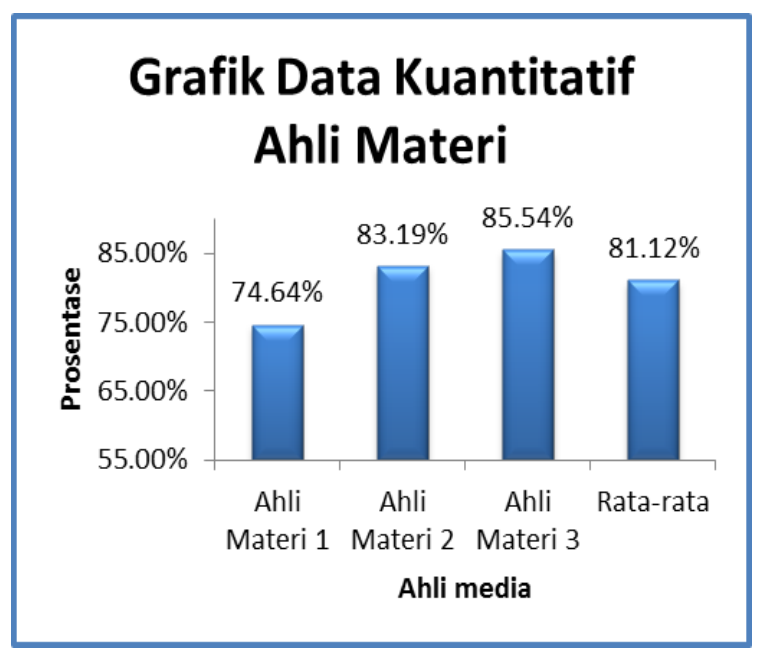

(b)

GAMBAR 2. (a) Grafik data kuantitatif ahli media, (b) grafik data kuantitatif ahli media

Data kualitatif para ahli media ditunjukkan dengan komentar dan saran yang telah diberikan oleh para ahli. Saran yang diberikan oleh para ahli media antara lain: (a) penulisan persamaan harus mengacu dengan penulisan sistem besaran dan satuan intenasional; (b) tata warna, gambar-gambar pendukung lebih diperbanyak; (c) login siswa dapat disajikan secara baik. Dari komentar dan saran yang diberikan ahli media, telah dilakukan perbaikan media.

TABEL 2. Data kuantitatif ahli media

\begin{tabular}{cccc}
\hline Aspek Validiasi & Ahli Media 1 & Ahli Media 2 & Ahli Media 3 \\
\hline Tampilan produk & $75 \%$ & $87,5 \%$ & $75 \%$ \\
Desain visual dan audio & $81,25 \%$ & $81,25 \%$ & $81,25 \%$ \\
Organisasi dan navigasi & $87,5 \%$ & $80,56 \%$ & $87,5 \%$ \\
Kemanfaatan & $75 \%$ & $81,25 \%$ & $75 \%$ \\
Rata-rata & $87,5 \%$ & $82,64 \%$ & $87,5 \%$ \\
\hline
\end{tabular}

Data kuantitatif ahli materi terhadap produk yang dikembangkan dapat dilihat pada TABEL 3. Untuk grafik data kuantitatif ahli materi ditunjukkan pada GAMBAR 2(b).

Selain data yang berbentuk kuantitatif, untuk menentukan validitas suatu produk juga digunakan data kualitatif. Data kualitatif berbentuk komentar atau saran dari para ahli. Saran para ahli di antaranya adalah: (a) contoh soal untuk menambah pengetahuan siswa; (b) penulisan materi agar diperbaiki sesuai dengan tata tulis yang benar; (c) untuk penilaian, angka harus ditampilkan. Dari komentar dan saran yang diberikan oleh para ahli materi, telah dilakukan perbaikan media.

TABEL 3. Data kuantitatif ahli materi

\begin{tabular}{cccc}
\hline Aspek Validiasi & Ahli Materi 1 & Ahli Materi 2 & Ahli Materi 3 \\
\hline Pembelajaran & $77,78 \%$ & $86,11 \%$ & $86,11 \%$ \\
Kebenaran isi & $71,15 \%$ & $88,46 \%$ & $78,85 \%$ \\
Kemanfaatan & $75 \%$ & $75 \%$ & $91,67 \%$ \\
Rata-rata & $74,64 \%$ & $83,19 \%$ & $85,54 \%$ \\
\hline
\end{tabular}

Hasil analisis data diperoleh dari angket yang diberikan kepada pakar-pakar ahli media dan ahli materi. Analisis data bertujuan untuk mengetahui kelayakan produk media pembelajaran berbasis 
website untuk pengembangan model pembelajaran blended learning. Adapun hasil dari pengujian yang telah dilakukan didapatkan kelayakan media dari hasil pengujian ahli media dengan rata-rata $80,56 \%$, maka dapat disimpulkan bahwa media pembelajaran ini masuk pada kriteria "Baik" ditinjau dari segi medianya. Sedangkan dari segi materi didapatkan kelayakan materi dari hasil pengujian ahli materi dengan rata-rata $81,12 \%$, maka dapat disimpulkan bahwa media pembelajaran ini masuk kriteria "Baik".

Penelitian ini menghasilkan produk berupa media pembelajaran berbasis website pada pokok bahasan listrik statis. Produk ini telah diuji oleh para ahli dari segi media dan segi materi. Hasil uji menunjukkan bahwa media pembelajaran telah memenuhi syarat kelayakan dengan kriteria yang baik.

\section{KESIMPULAN}

Berdasarkan penelitian dan pembahasan yang telah diuraikan maka dapat ditarik kesimpulan bahwa telah berhasil dirancang model pembelajaran blended learning yang menghasilkan media pembelajaran berbasis website untuk setiap jenis gaya belajar. Dari penilaian yang dilakukan oleh para ahli media menunjukkan kriteria baik dengan nilai rata-rata $80,56 \%$. Sedangkan dari penilaian yang dilakukan oleh para ahli materi menunjukkan kriteria baik dengan nilai rata-rata sebesar $81,12 \%$.

\section{UCAPAN TERIMAKASIH}

Terimakasih kepada pihak pemberi dana penelitian, kepada lembaga yang membantu penelitian, serta pihak yang terkait dalam diskusi.

\section{REFERENSI}

Hasrul 2009, 'Pemahaman tentang gaya belajar', Jurnal MEDTEK, vol. 1 no. 2, pp. 67-76

Hermawanto, S. Kusairi, Wartono 2013, 'Pengaruh blended learning terhadap penguasaan konsep dan penalaran fisika peserta didik kelas X', Jurnal Pendidikan Fisika Indonesia, vol. 9, pp. 67-76

Husamah 2014. Pembelajaran Bauran (Blended Learning) Terampil Memadukan Keunggulan Face to face, E-learning Offline Online dan Mobile Learning. Jakarta, Prestasi Pustaka, p. 21

L. I. Pradnyawati, I. N. Suparta, Sariyasa 2014, 'Pengaruh strategi blended learning dalam pembelajaran kooperatif terhadap motivasi belajar matematika ditinjau dari gaya belajar siswa di smp k 2 harapan', Universitas Pendidikan Ganesha, Singaraja, pp. 3

M. Ali 1995, Penelitian kependidikan prosedur \& strategi. Bandung, Angkasa (1995), p. 184.

P. B. De, H. Mike (Eds. Sari Meutia) 2005, Quantum learning membiasakan belajar nyaman dan menyenangkan, Bandung, Kaifa, pp. 110

S. Arikunto 2010, prosedur penelitian suatu pendekatan praktik. Jakarta: Rineka Cipta, p. 284.

Sugiyono 2009, Metode penelitian pendidikan pendekatan kuantitatif, kualitatif, dan $r \& d$, Bandung, Alfabeta, p. 407

Yusuf,M. T. 2011, 'Mengenal blended learning', Lentera Pendidikan, Vol. 14, No. 2, pp. 232-242 